This article has been scanned by iThenticat No plagiarism detected

Volume 3, Issue 4, August 2021

p. 232-241

\title{
SUPPORTERS OF THE ORIGINALITY OF ARABIC GRAMMAR
}

http://dx.doi.org/10.47832/2757-5403.4-3.20

\section{Slimane BAHNYNY ${ }^{1}$}

\begin{abstract}
:
Some orientalists doubted the authenticity of Arabic grammar, followed by some Arab thinkers. In this article, I tried to show that the upgrowth of Arabic grammar arose far from any foreign influence, whether this influence was direct from Indian culture or Greek culture, or indirectly through The impact of translations made by these two cultures at the hands of the Persians of the Syriacs, and I used in this matter the opinions of Arab and foreign thinkers who supported the emergence of Arabic grammar Under the auspices of the Arab-Islamic culture, such as: Muhammad Al-Tantawi, who acknowledged the originality of Arabic grammar. And Abdel-Fattah Al-Dajani, who refuted any Greek or Syriac influence on him. And Abed Al-Jabri, who tried to differentiate between the Aristotelian and Arabic categories. And Muhammad Khair Al-Halawani, who tried to respond to all those who claimed foreign influence on the Arabic grammar. Littmann, who showed that the Arabic grammar arose away from any for.
\end{abstract}

Key words: Arabic Grammar, Supporters, Orientalists.

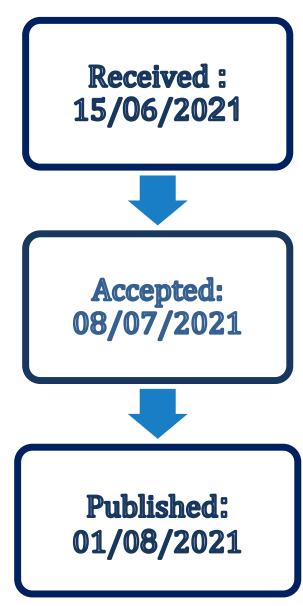

\footnotetext{
${ }^{1}$ Researcher, Ibn Tofail University, Morocco, slimanebahnyny1@gmail.com, https://orcid.org/0000-0002-5577$\underline{1633}$
}

Copyright $(\mathcal{C}$ Published by IJHER Journal, www.ijherjournal.com

Rimar Academy, Fatih, Istanbul, 34093 Turkey

All rights reserved 


\section{الموئيدون لأصالة النحو العربي}

سليمان باحنيني

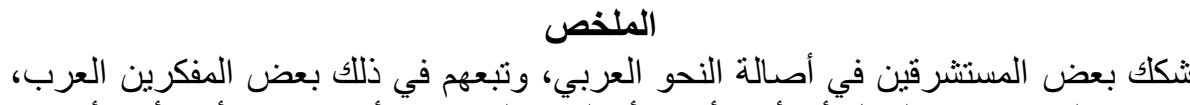

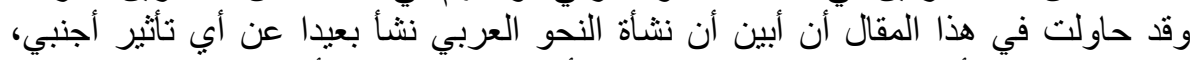

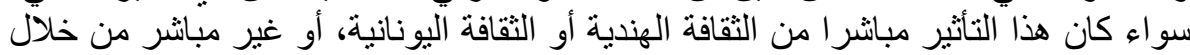

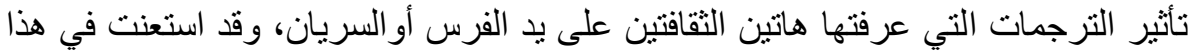

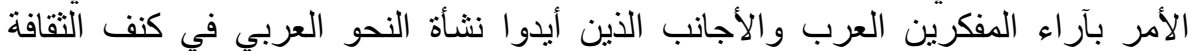

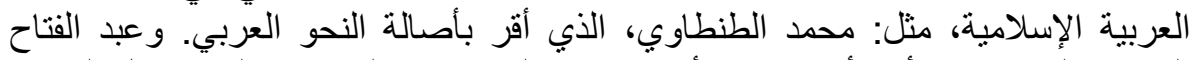

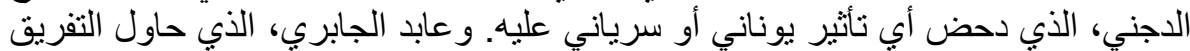

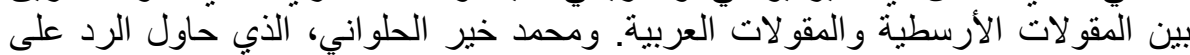

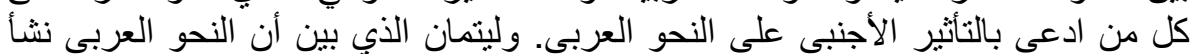

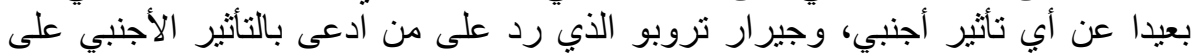

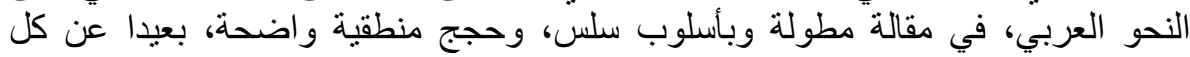

الكلمات المفتاحية: النحو العربي، المؤيدون، المسنشرقين. 


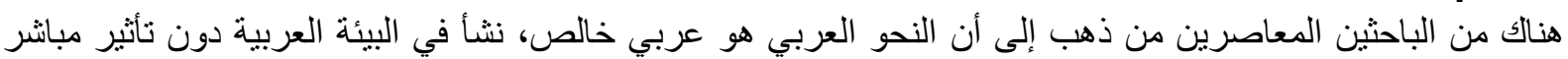

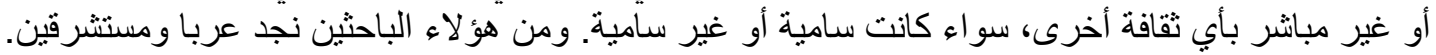

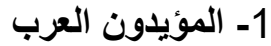

ومن الدفكرين العرب الذين قالوا بأصالة النحو العربي نجد الطنطاوي، حيث بقول: "نثأ النحو في العر اق صدر الإسلام

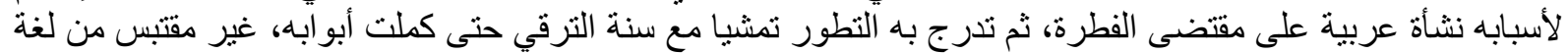

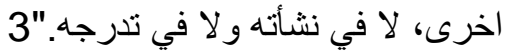

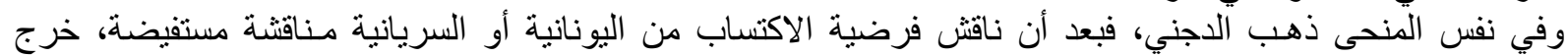

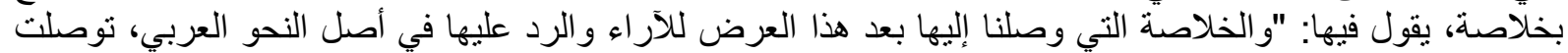

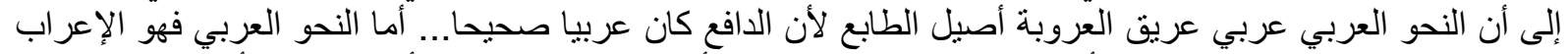

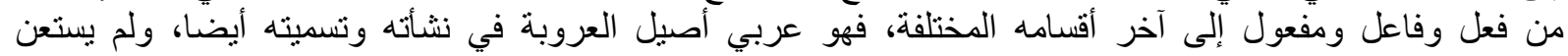

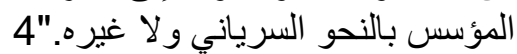

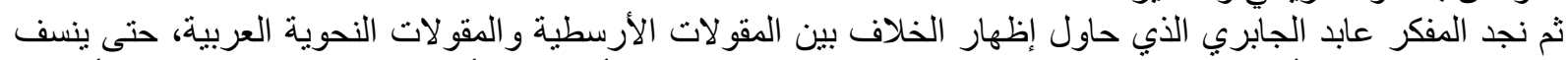

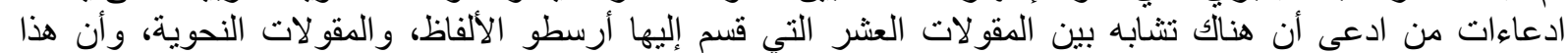

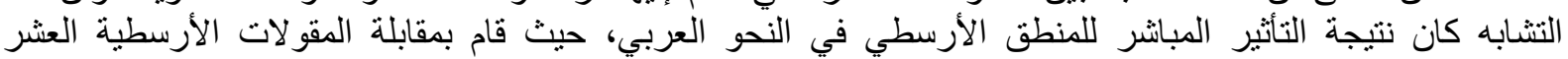

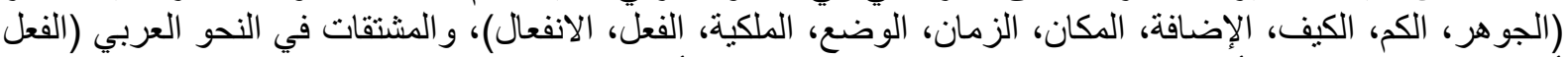

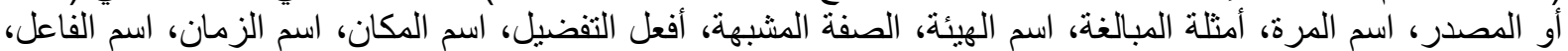

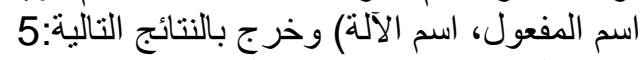

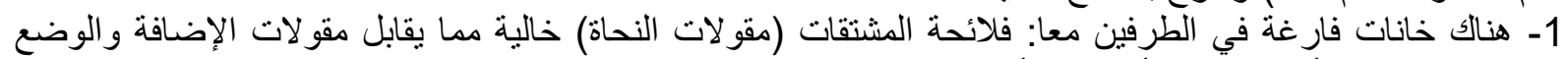

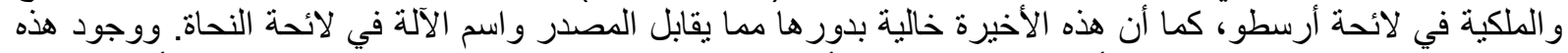

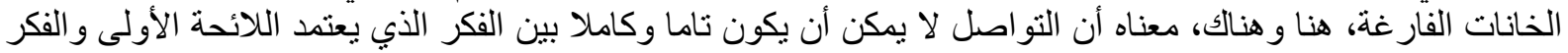

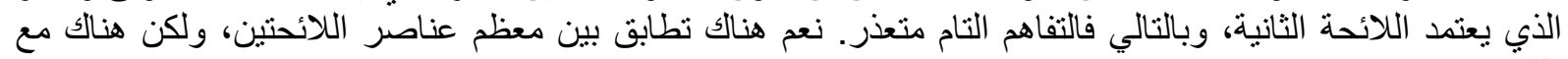

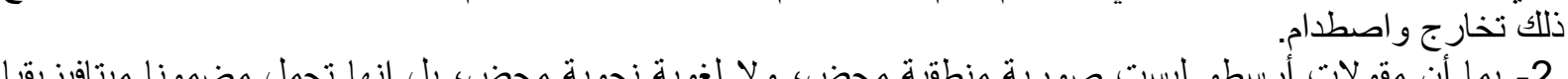

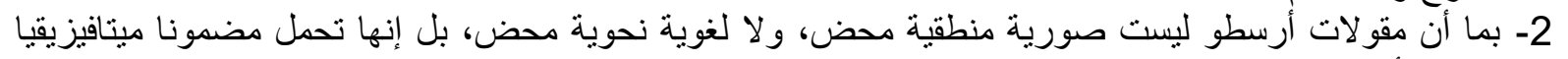

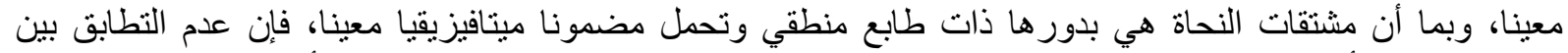

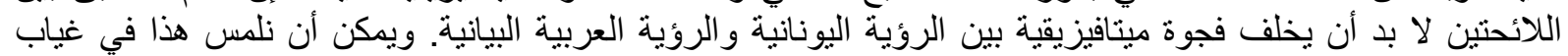

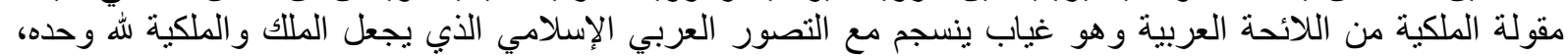

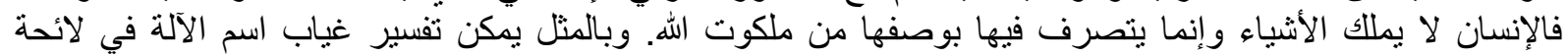

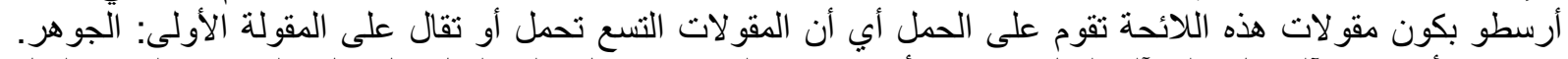

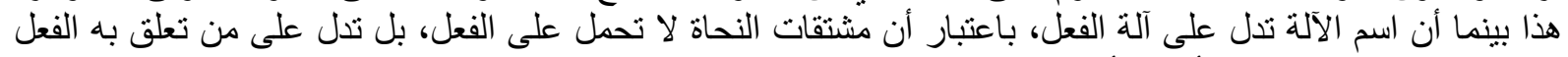

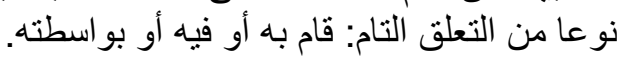

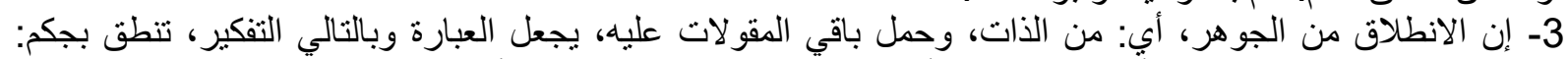

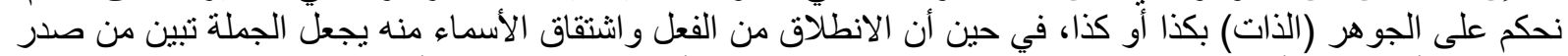

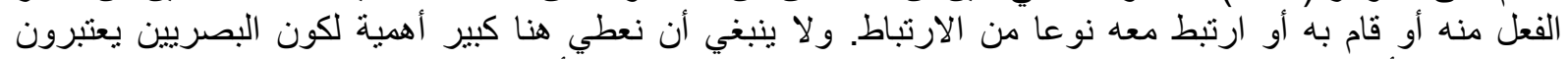

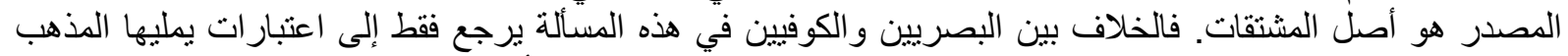

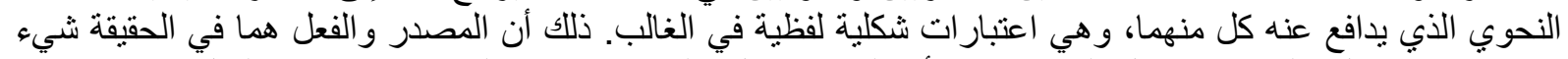

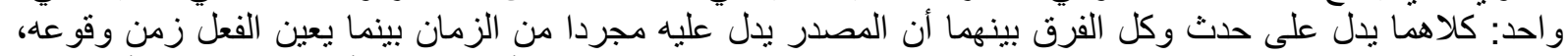

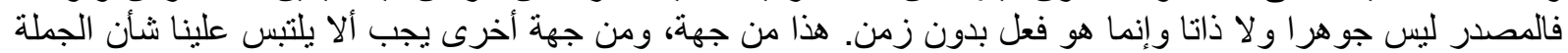

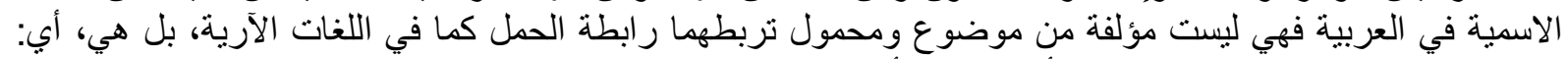

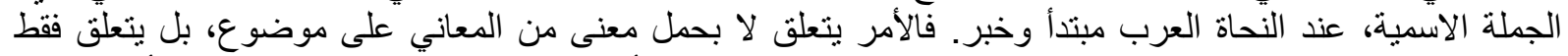

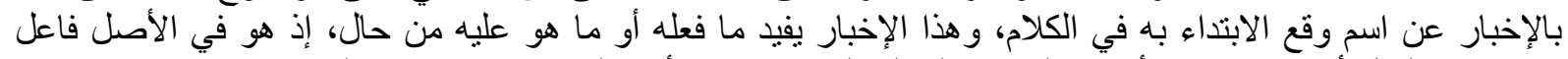

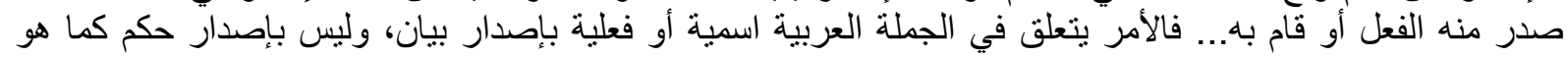
الحال في الجملة اليونانية، وفي اللغات الآرية بكيفية عامة.

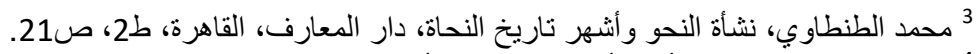

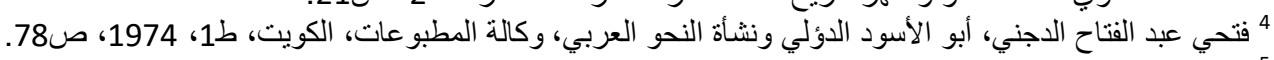

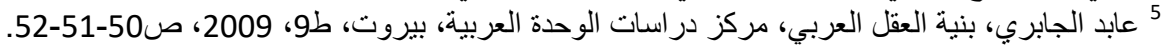




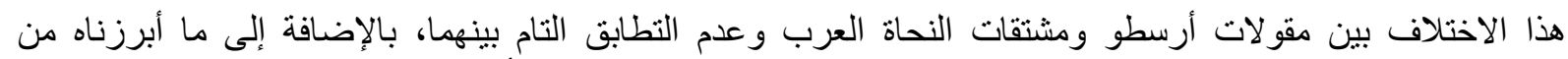

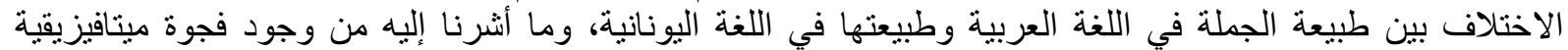

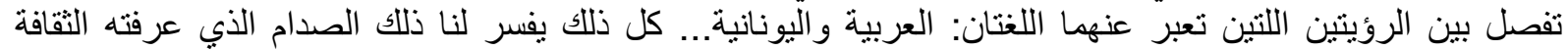

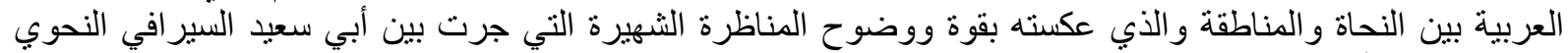

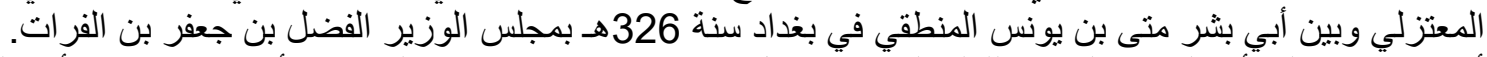

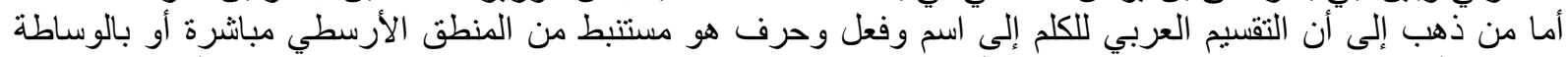

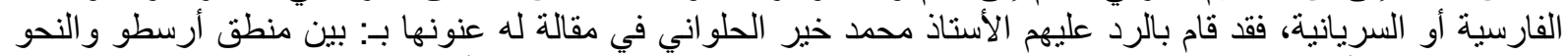

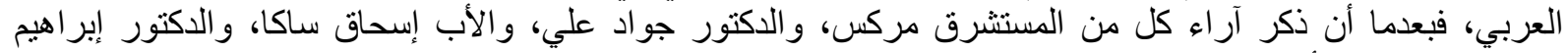

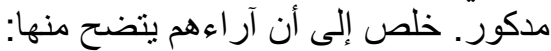

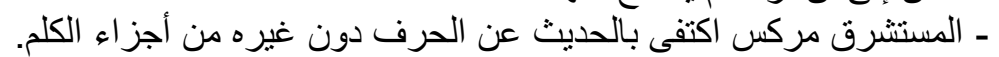

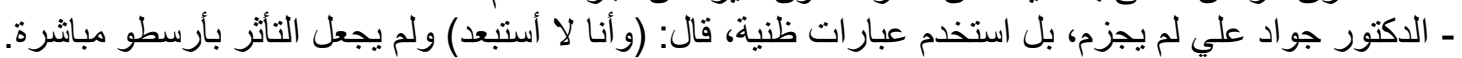

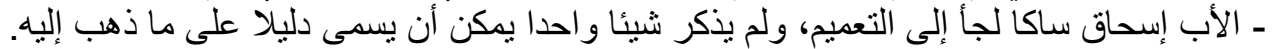

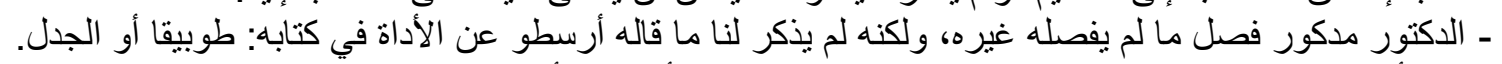

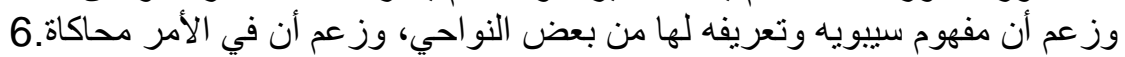

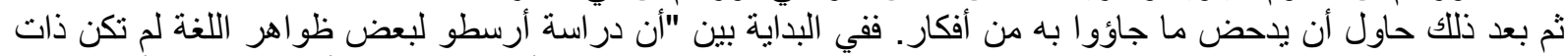

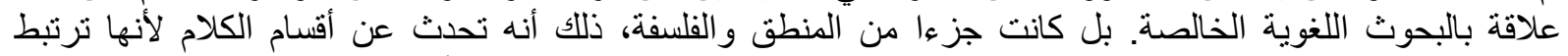

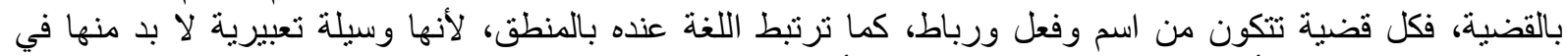

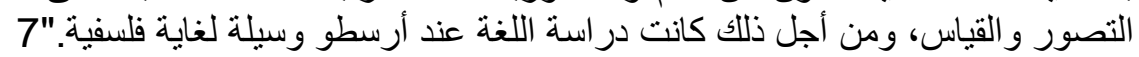

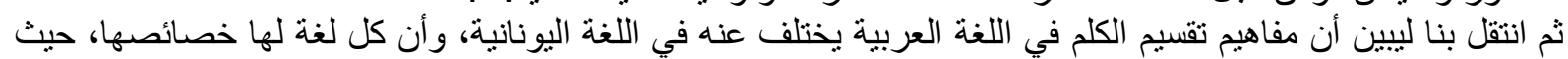

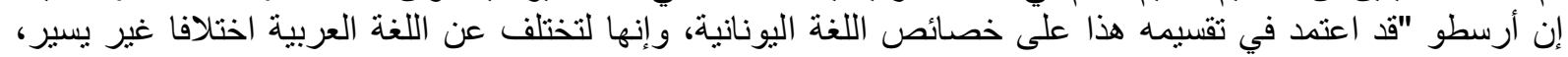

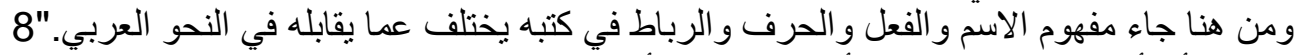

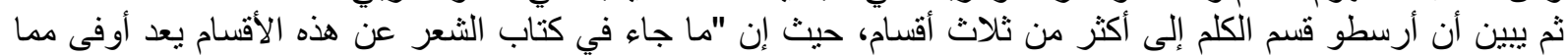

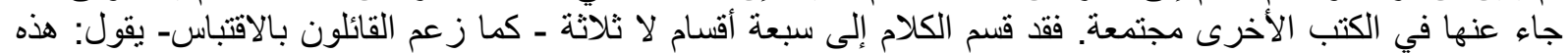

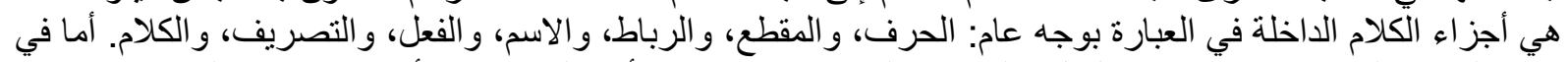

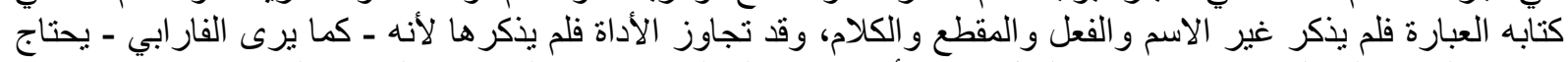

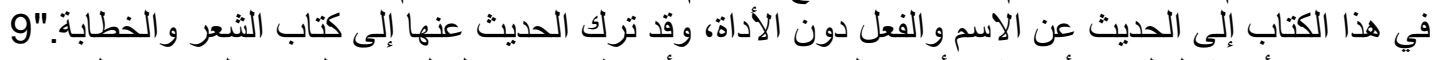

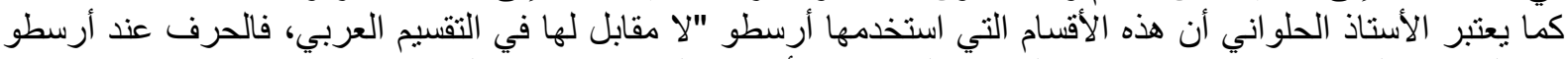

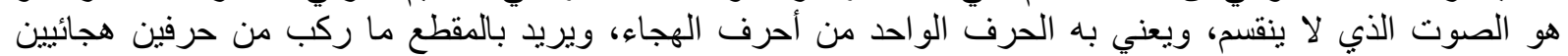

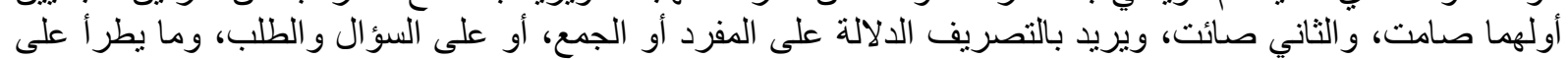

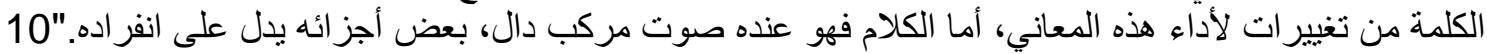

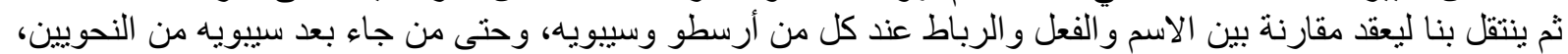

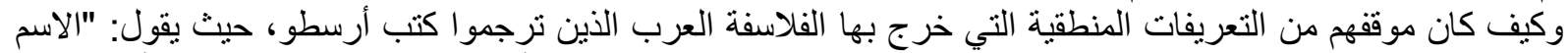

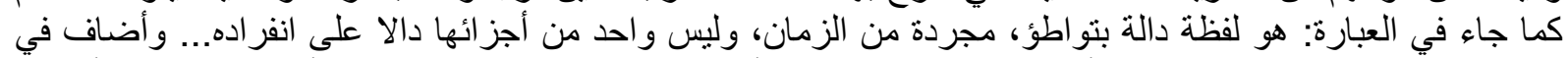

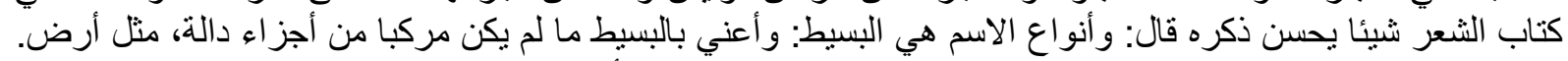

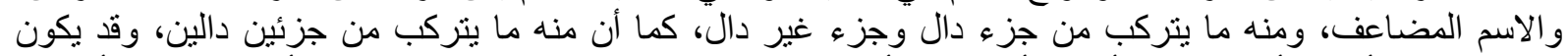
الاسم ثلاثي الأجزاء أو رباعي الأجزاء أو كثنير الأجزاء

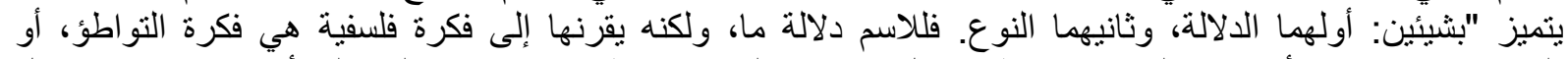

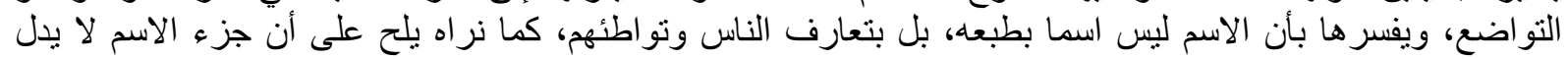

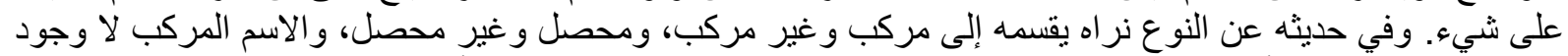

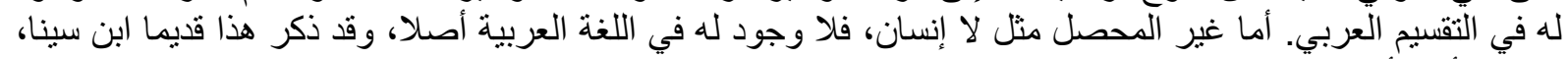

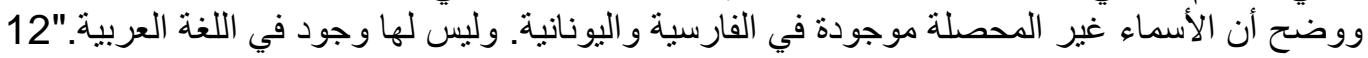

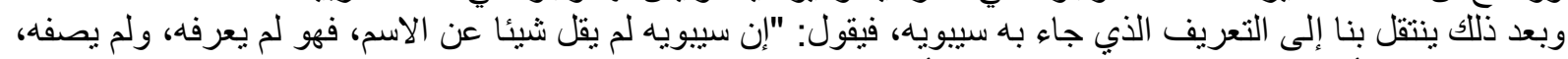

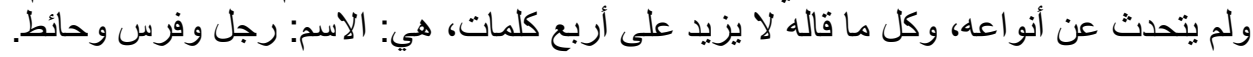

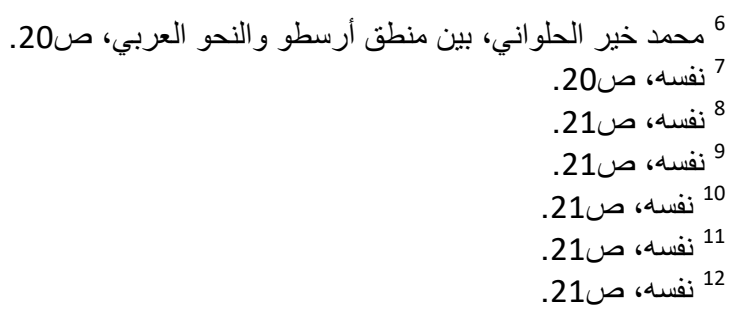




\section{SUPPORTERS OF THE ORIGINALITY OF ARABIC GRAMMAR}

بينما النحويون الذين جاؤوا بعد سييويه في القرن الثالث الهجري، وقد وققوا على منطق أرسطو، وحدوا النحو بمفاهيم

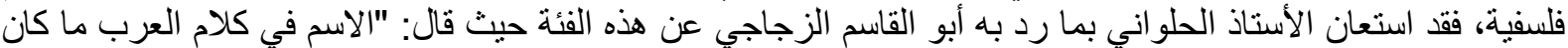

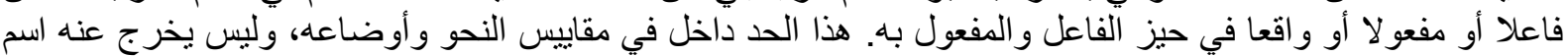

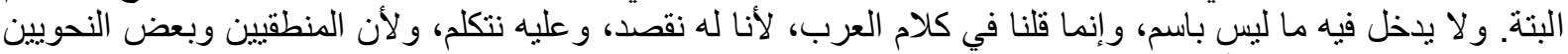

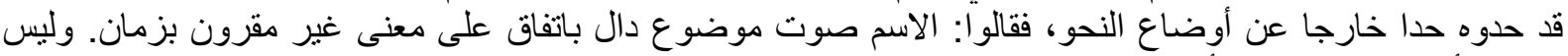

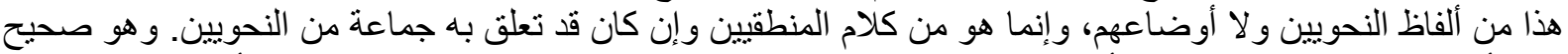

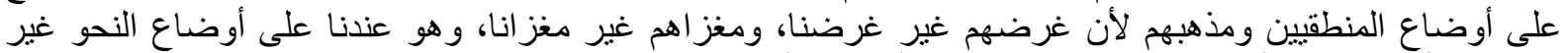

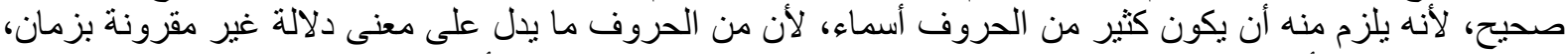

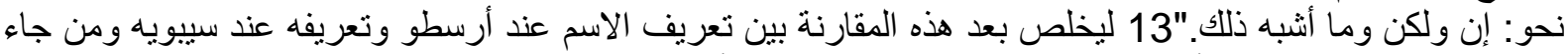

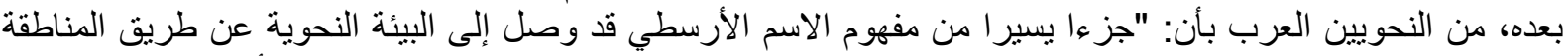

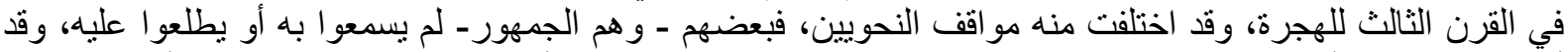

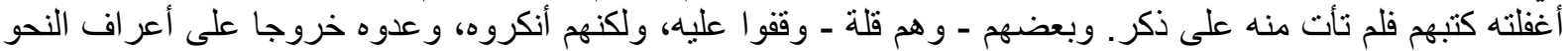

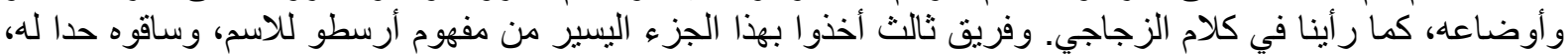

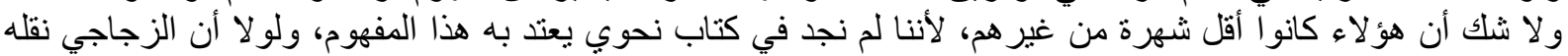

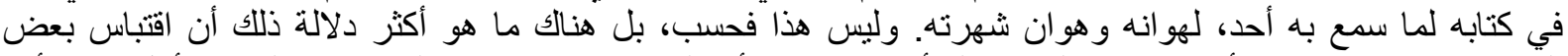

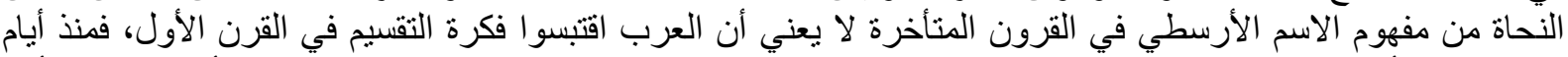

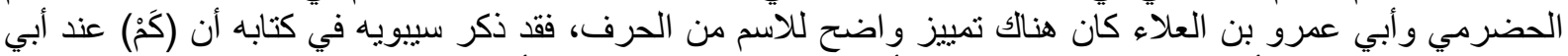

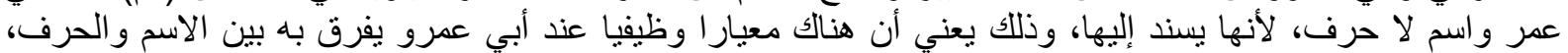

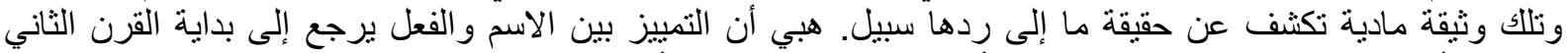

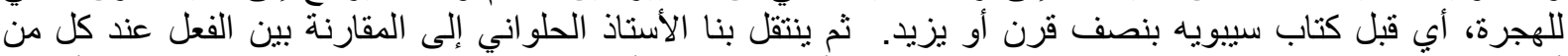

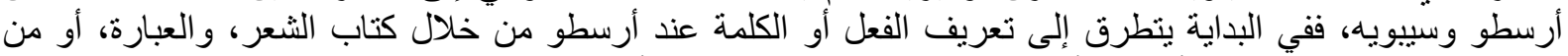

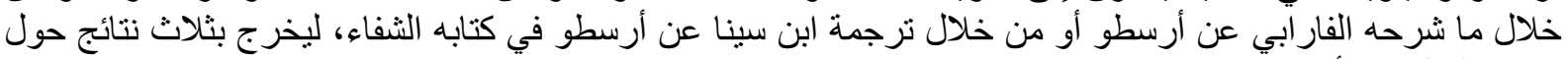

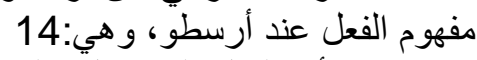

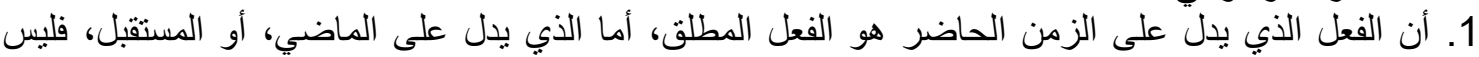

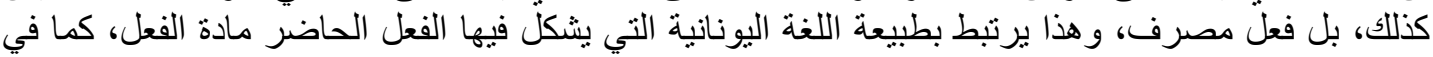

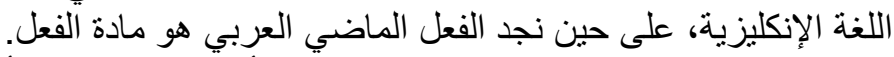
2. وكذلك لا يكون فعلا إلا إذا كان بصيغة الغئن الغئب، أما ما كان للمتكلم أو للمخاطب فلا يكون فعلا، بل عنده كلام

مركب. 3. أن الفعل يقال على شيء، أبي أنه في التعبير العربي سند، غير أن أرسطو يزيد في هذا، لأن طبيعة اللغة

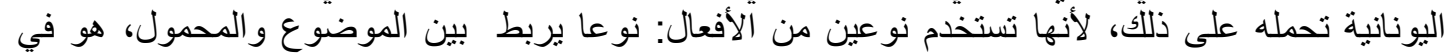

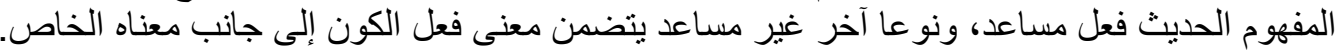

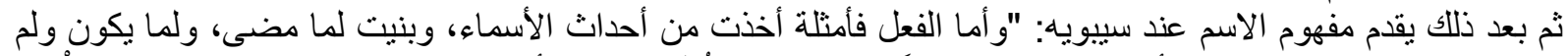

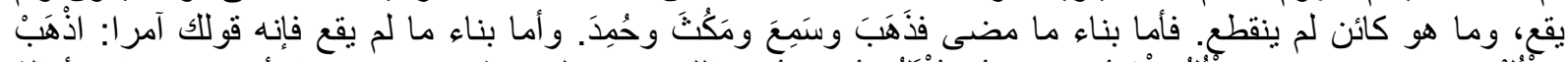

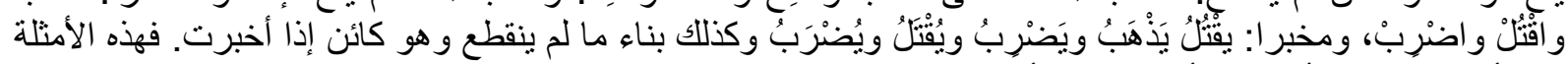

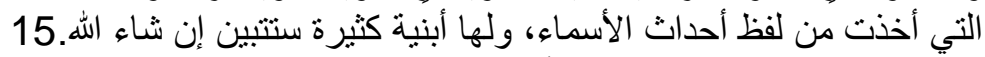

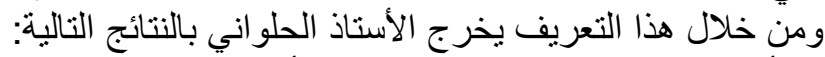

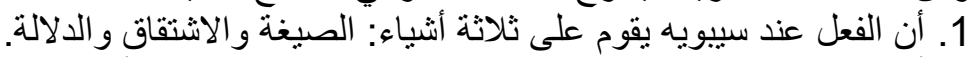

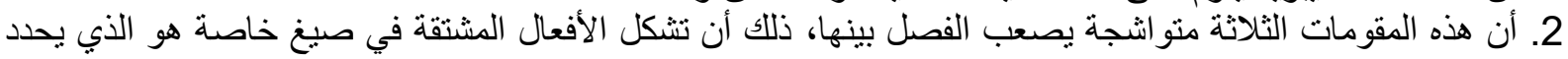

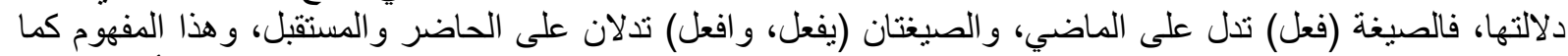

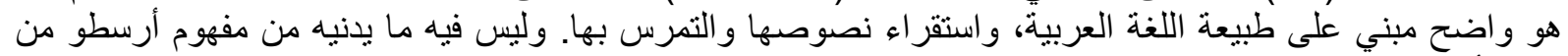
قريب أو بعيد.

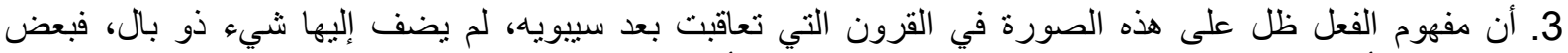

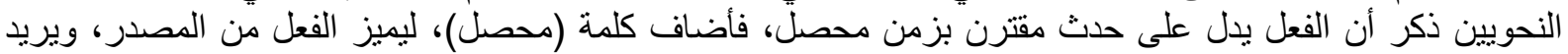
بها أن صيغة الفعل هي التي ندل على الزمان، وذكر آخر أنه ما أسند إلى غيره ولم يسند غيره

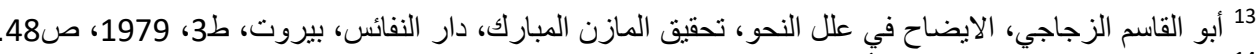

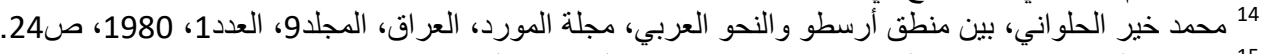

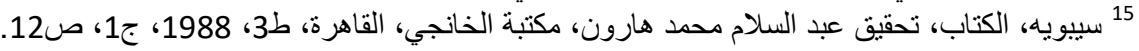


ثم انتقل بنا إلى مناقتشة مفهوم الحرف عند كل من سييويه وأرسطو، ليثبت أن لا علاقة بينهما. فطرح في البداية تعريف

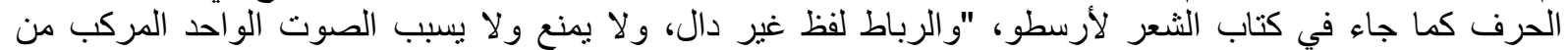

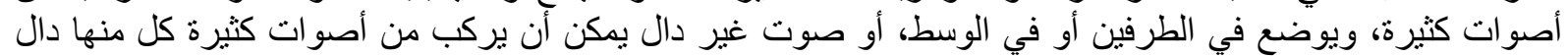

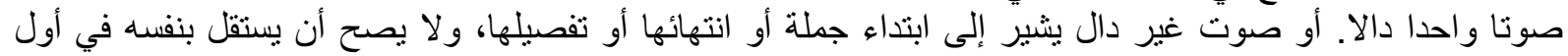

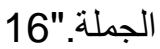

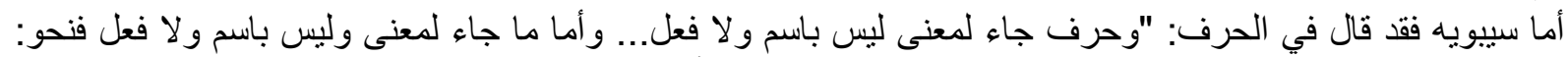

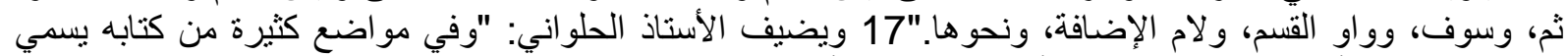

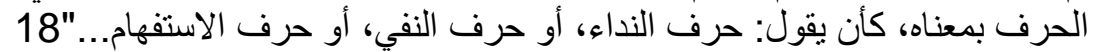
وبعد هذه المقارنة يخر جان الأستاذ الحلو اني بالنتائج التالية:

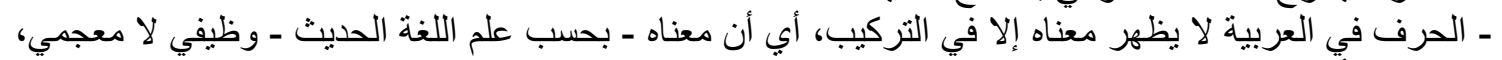

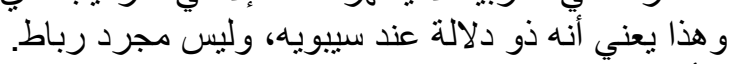

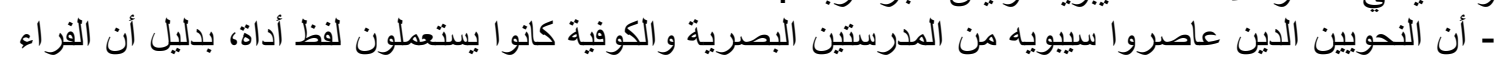

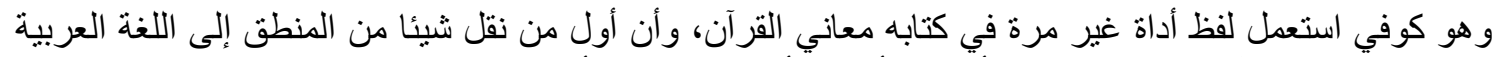

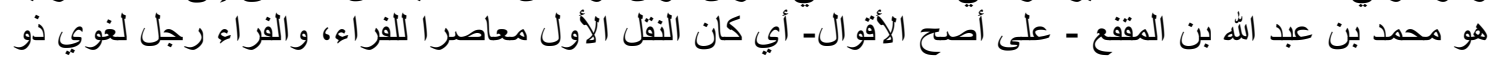

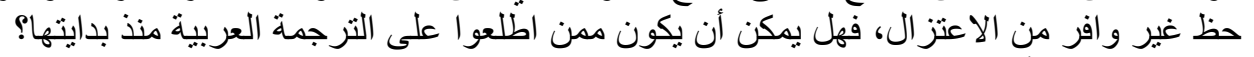

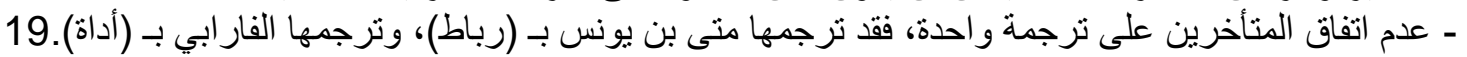

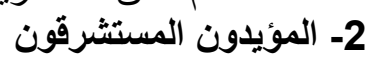

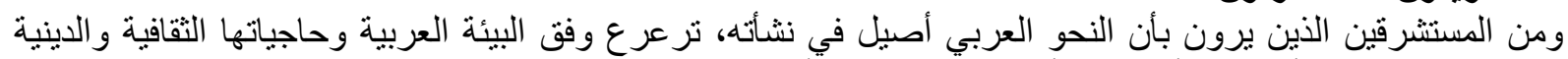

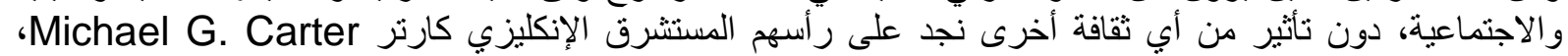

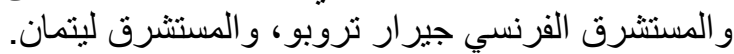

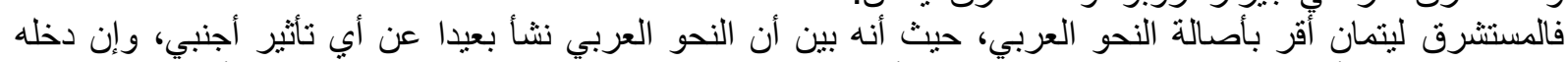

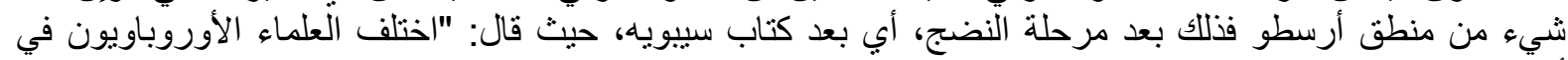

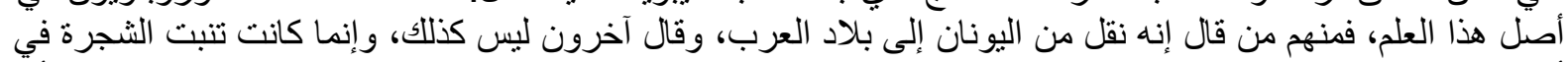

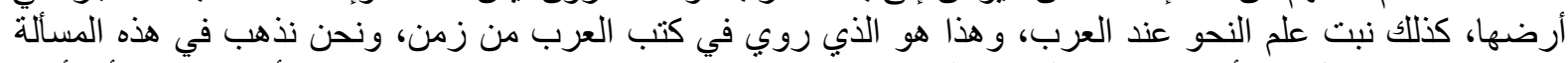

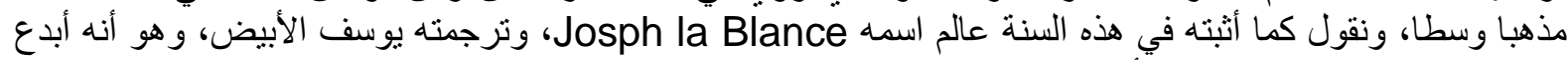

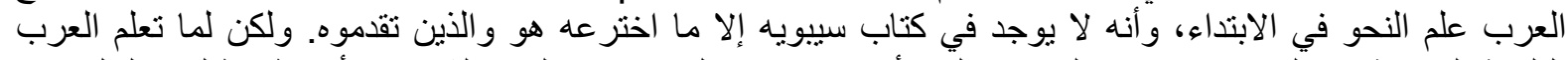

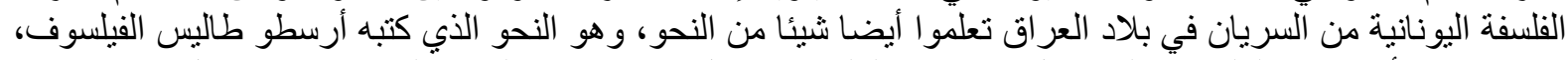

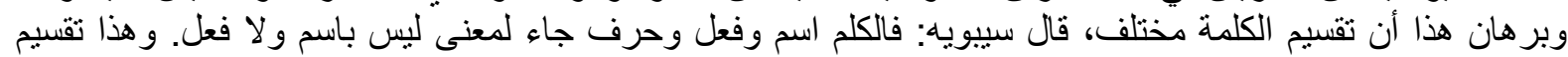

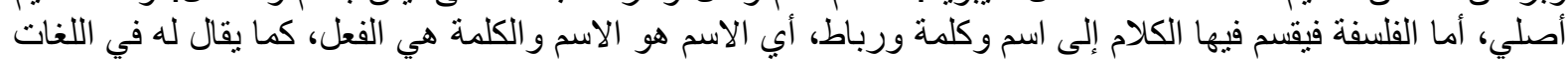

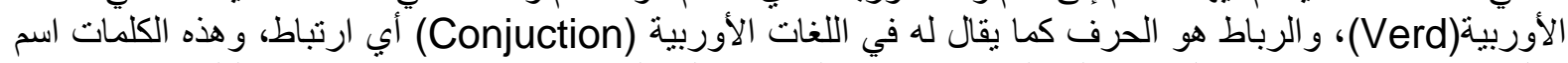

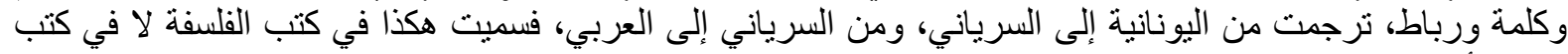

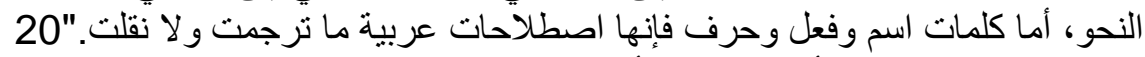

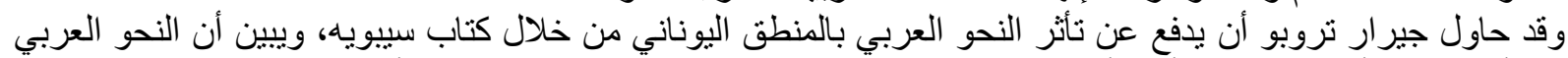

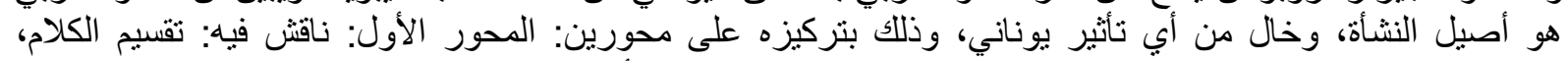

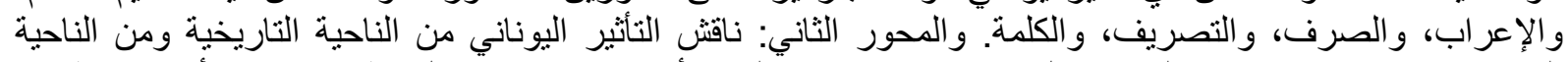

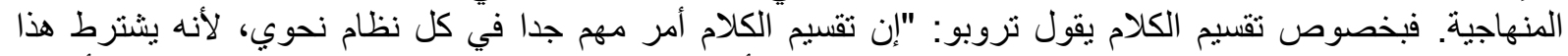

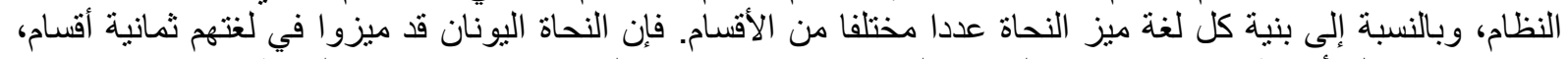

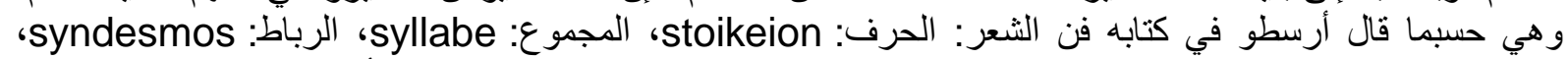

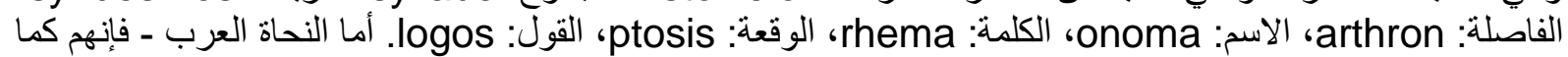

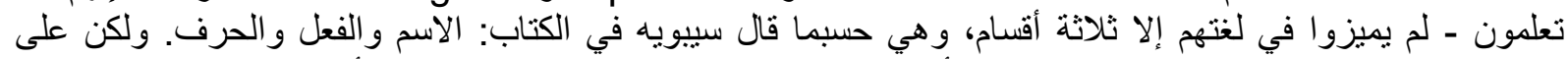

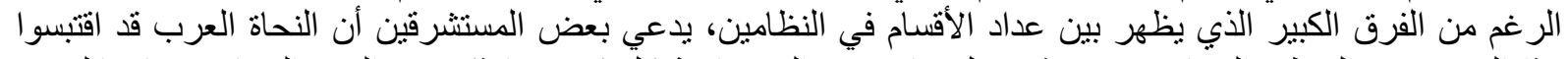

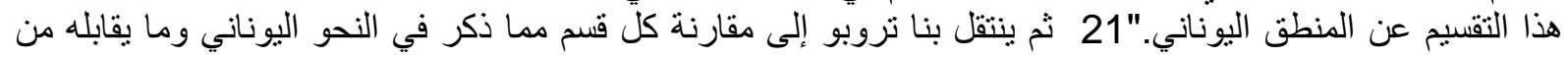

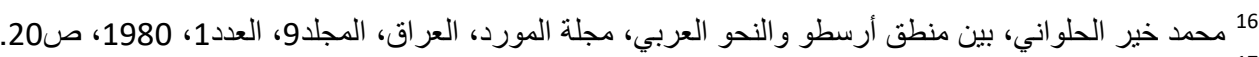

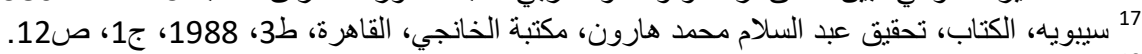

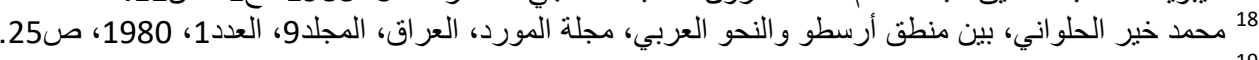

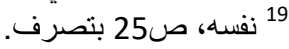

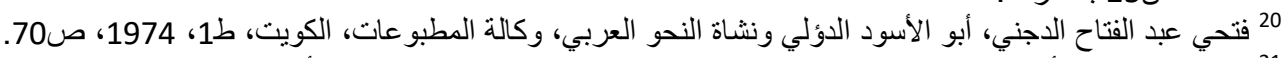

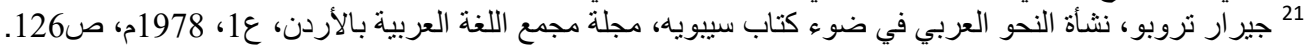




\section{SUPPORTERS OF THE ORIGINALITY OF ARABIC GRAMMAR}

النحو العربي، ليخلص إلى: "من الناحية اللسانية، يظهر لنا أنه من المستحيل أن يكون التقسيم العربي منقولا من التقسيم

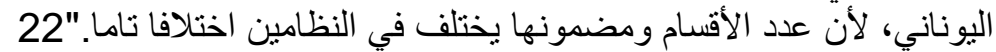

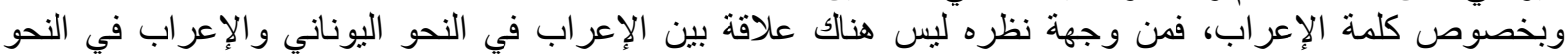

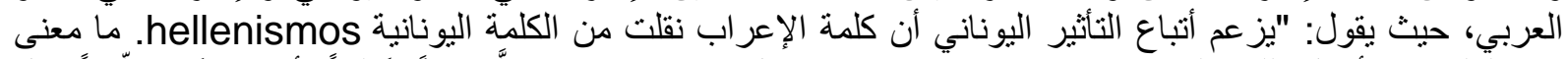

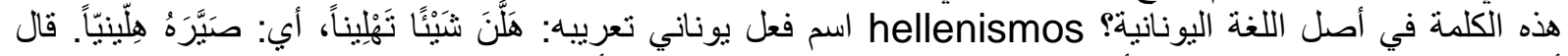

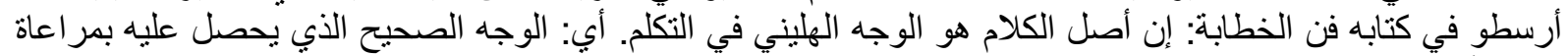

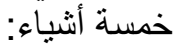
1- 1 باستعمال الروابط، أي حروف العطف. 2- 2 - باستعمال الكلمات الخاصة. 3- بعدم استعمال الكلمات الملتبسة. 4- ب بتمييز الأجناس في الأسماء. 5- 5 بتمييز الأعداد فيها.

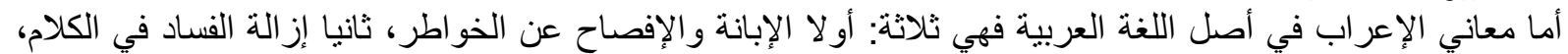

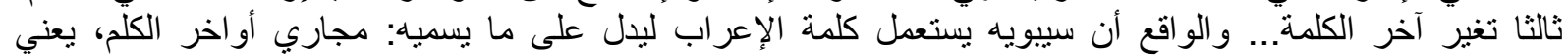

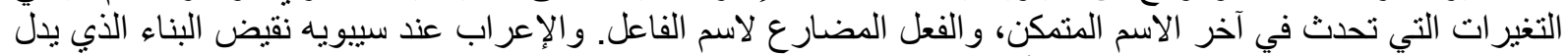

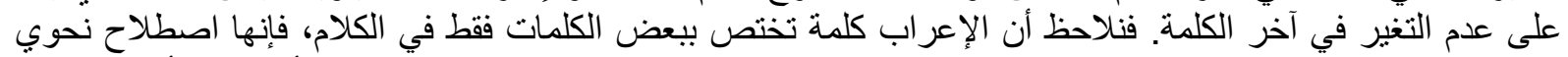

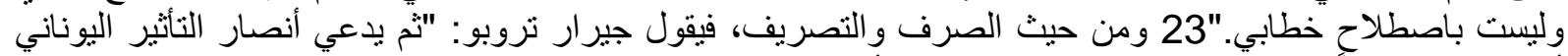

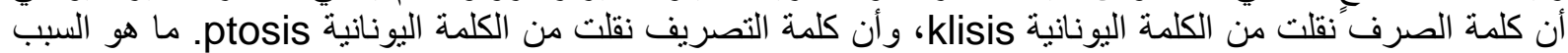

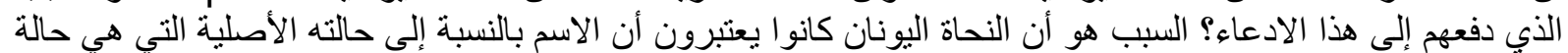

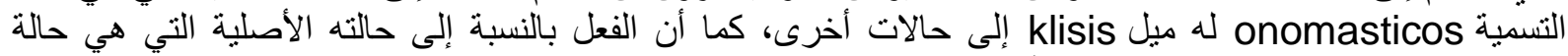

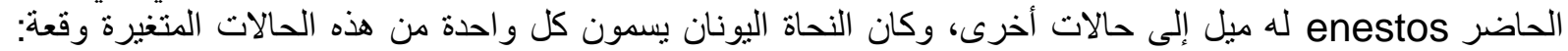

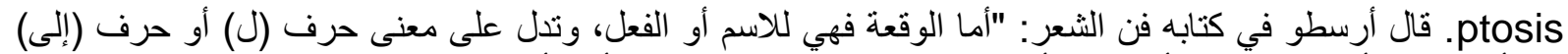

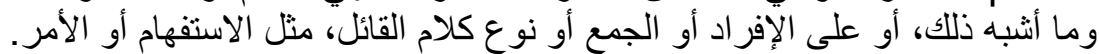

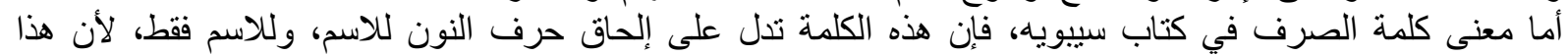

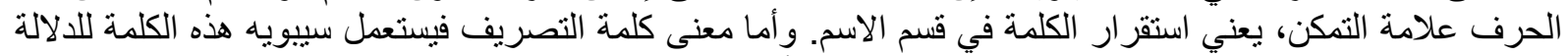

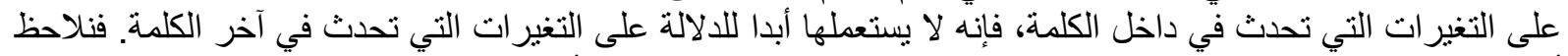

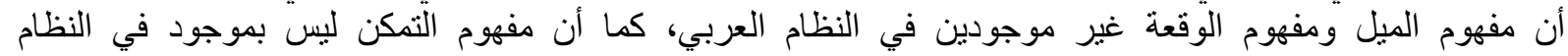

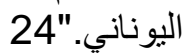

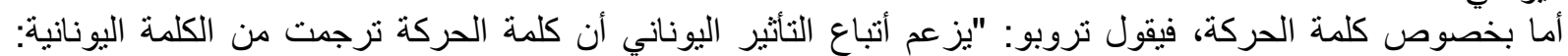

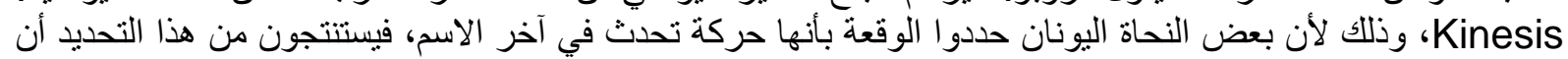

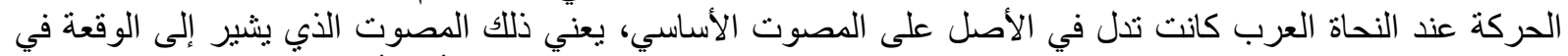

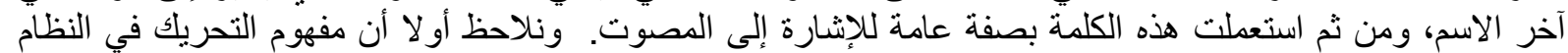

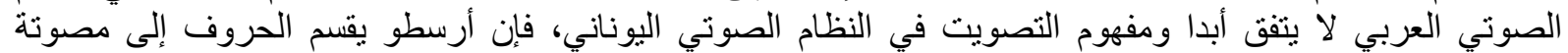

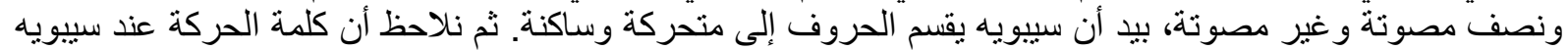

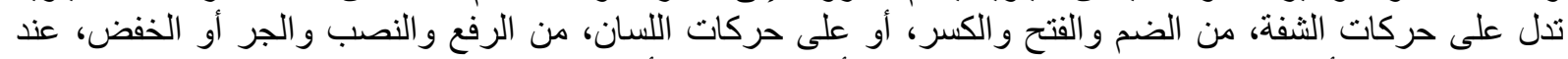

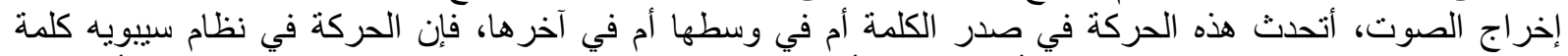

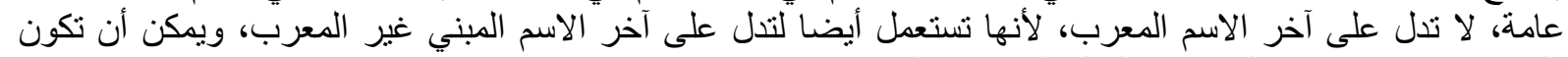

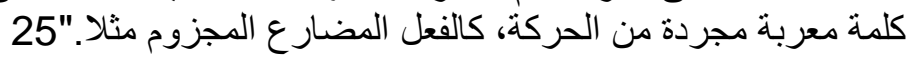

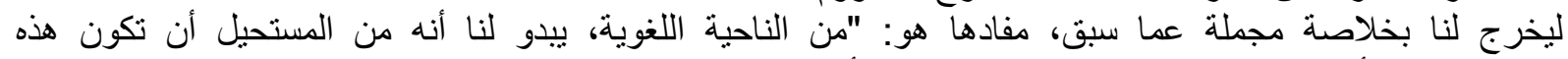

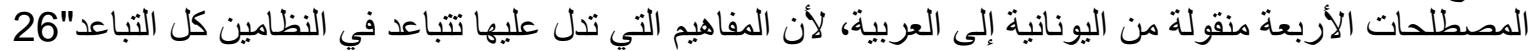

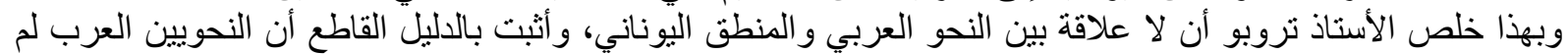

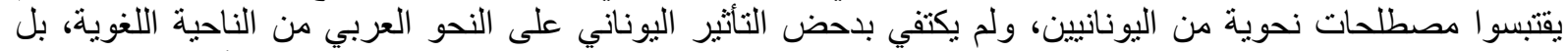

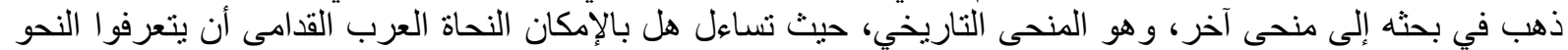
اليوناني و المنطق اليوناني فيتأثروا بهما؟

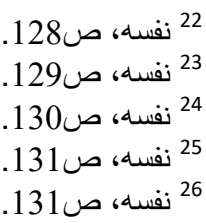




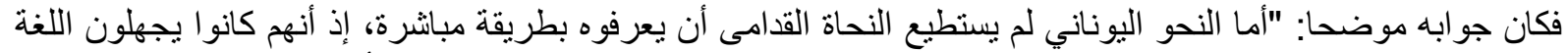

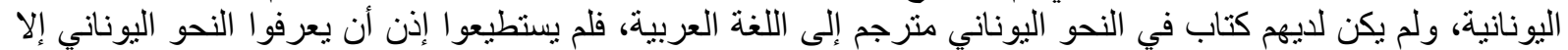

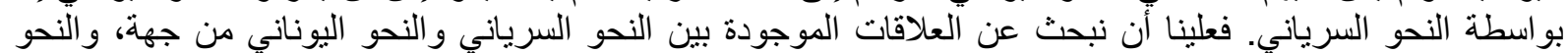

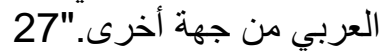

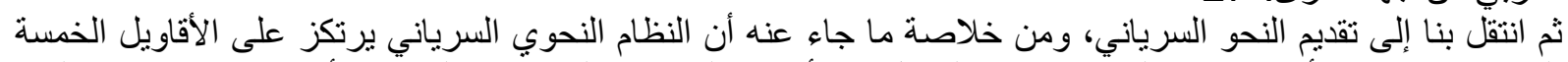

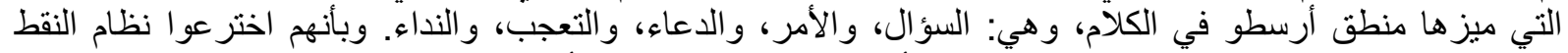

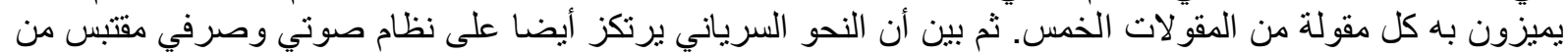

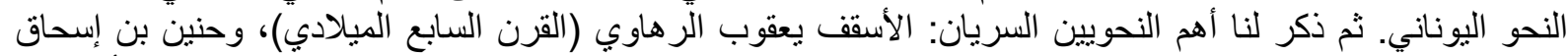

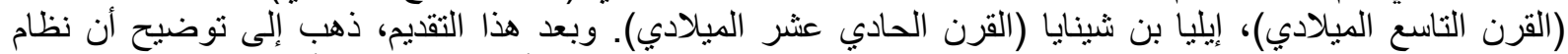

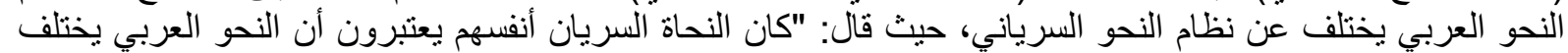

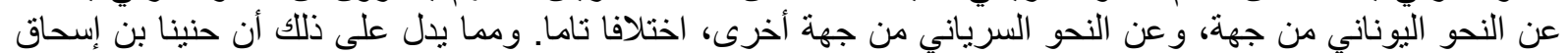

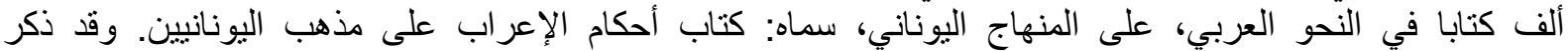

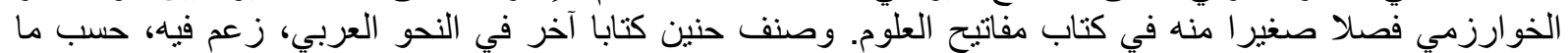

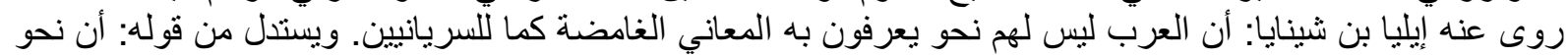

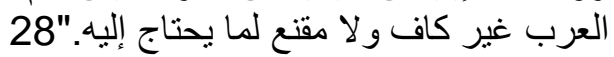
ثم بعد هذا يقدم لنا حوارا مهما دار بئ بين إيليا بن شينايا والوزير الحسين الحسين بن علي المغربي، ليوضح لنا نظام النحويين

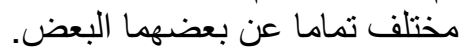

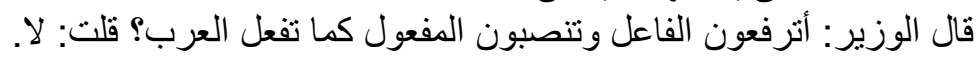

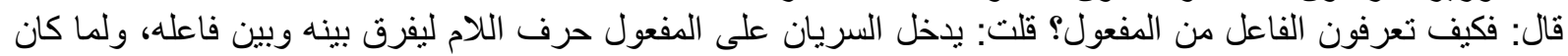

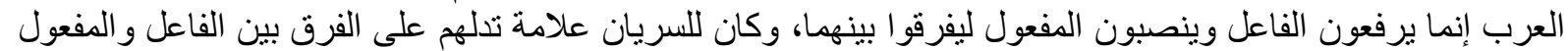

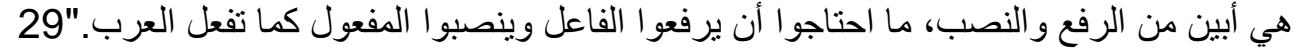

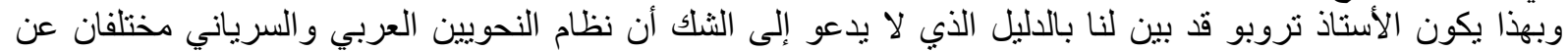

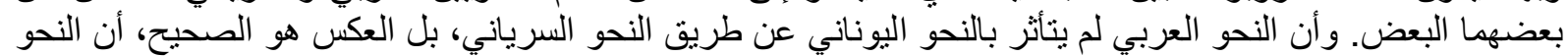

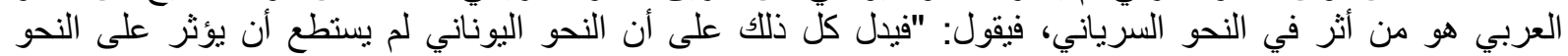

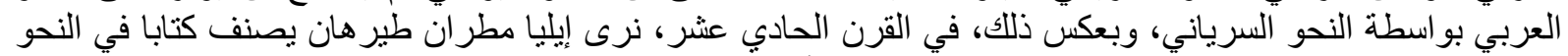

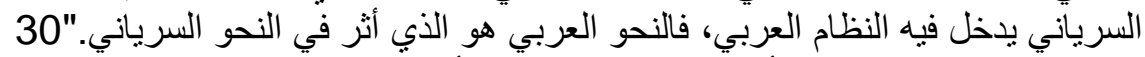

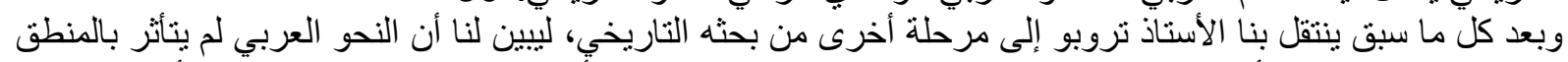

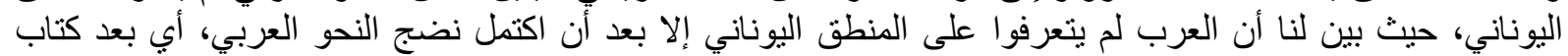

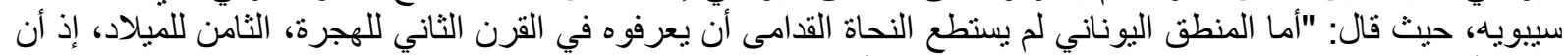

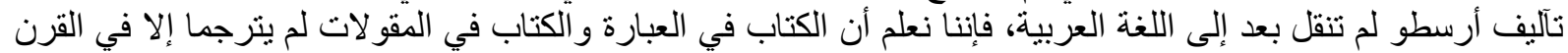

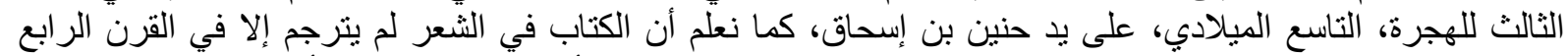

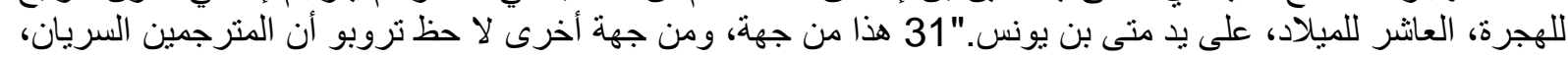

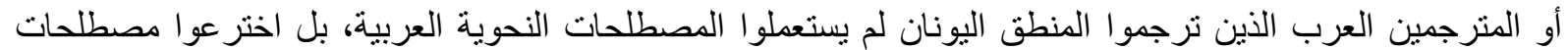

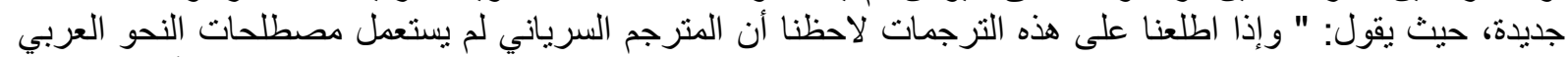

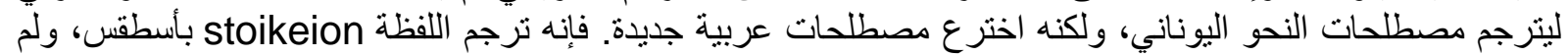

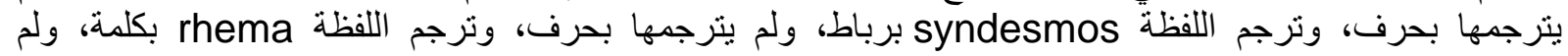
يترجمها بفعل، وترجم اللفظة klisis بميل، ولم يترجمها بإعراب، وترجم اللفظة phone بمصوت، ولم يترجمها

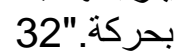
و أورد لنا تروبو نصا للفيلسوف العربي الفار ابي الذي عاش في القرن الر ابع للهجرة، العانشر للمبلاد، لبستشهد به ويبين لنا

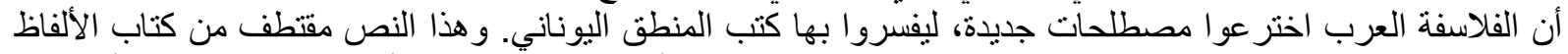

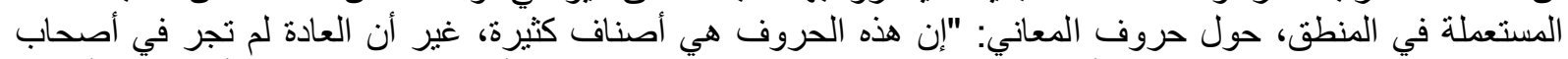

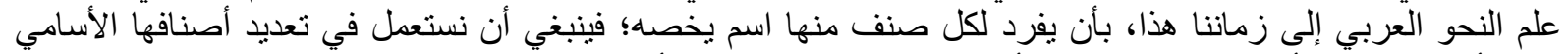

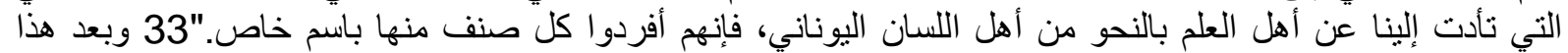

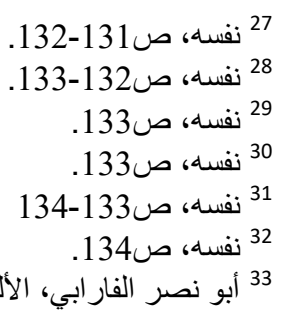

33 أبو نصر الفارابي، الألفاظ المستعملة في الدنطق، تحقيق محسن مهدي، دار المشرق، بيروت، ط 2، ص42. 


\section{SUPPORTERS OF THE ORIGINALITY OF ARABIC GRAMMAR}

الاستشهاد، قال تروبو: "فاخترع الفار ابي خمسة مصطلحات ليدل على هذه الأصناف من حروف المباف المعاني، وهي:

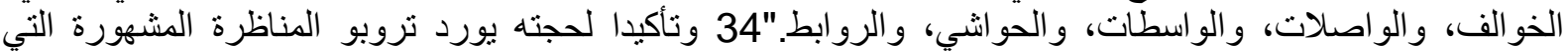

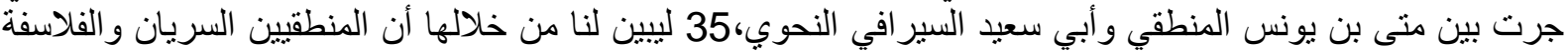

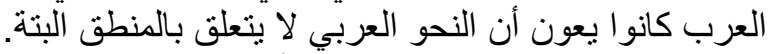

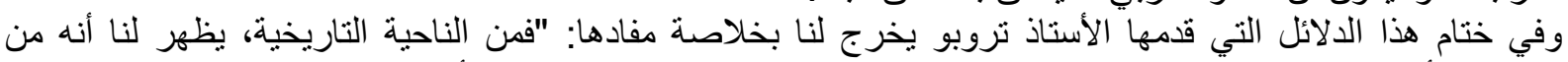

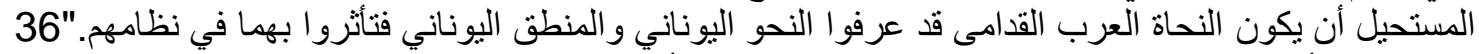

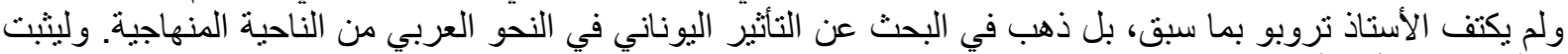

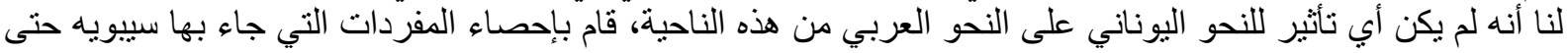

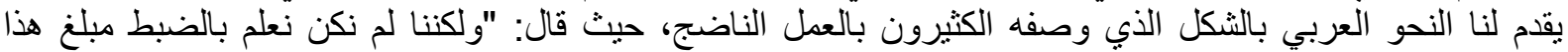

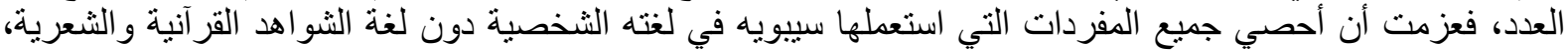

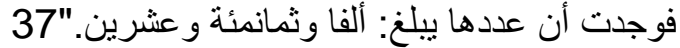

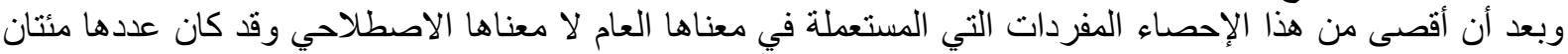

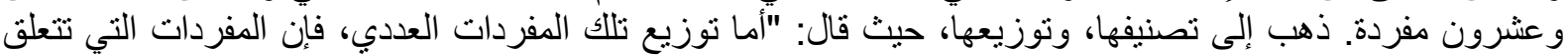

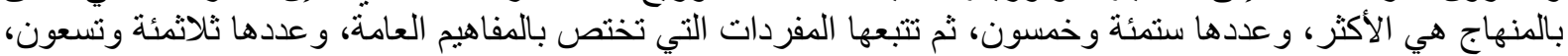

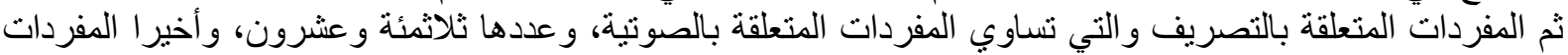

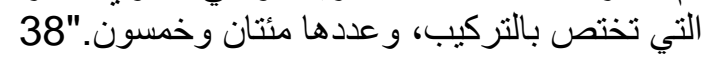

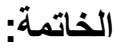

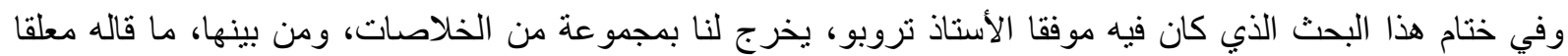

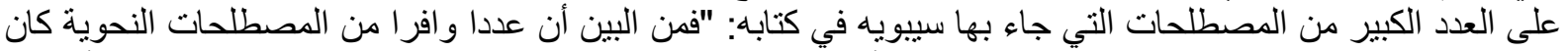

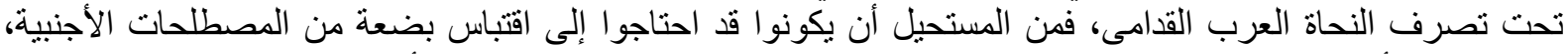

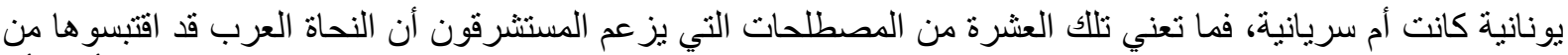

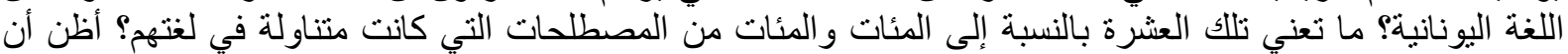

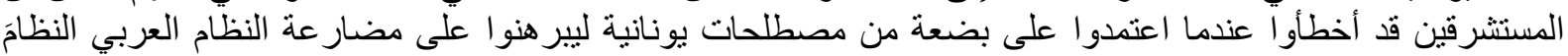

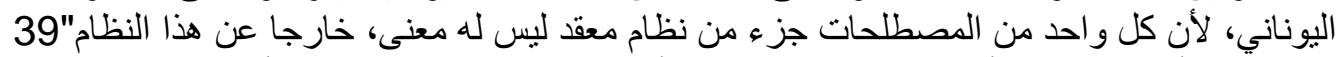

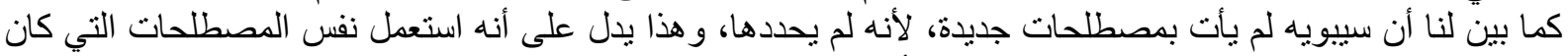

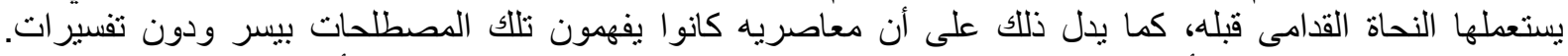

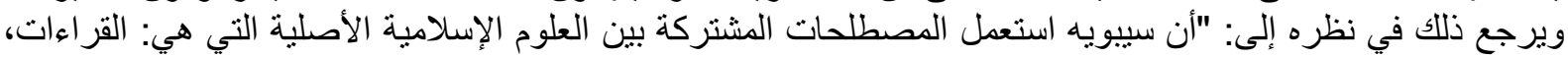

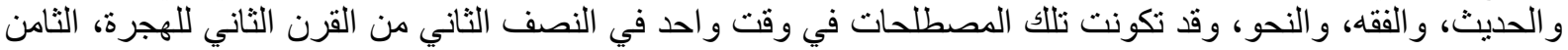

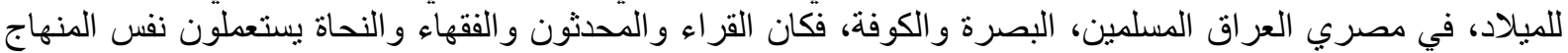
ونفس المفاهيم ونفس المصطلحات، لأنهم كانوا يقصدون إلى نفس الهدف الذي هو الذئ سلامة لغة التنزيل الإلهي والحديث

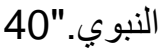

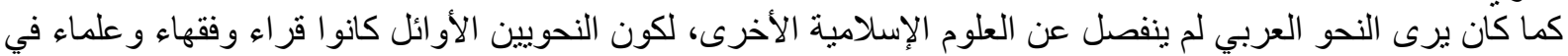

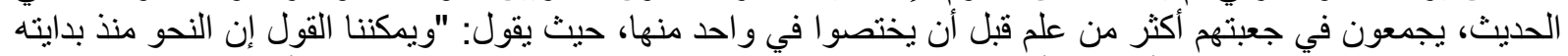

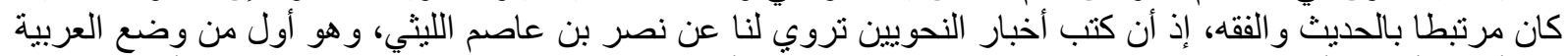

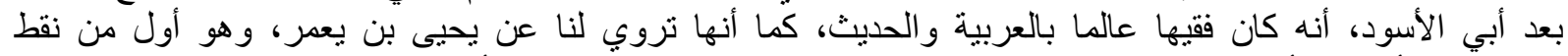

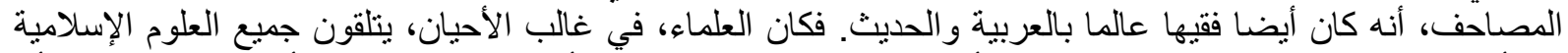

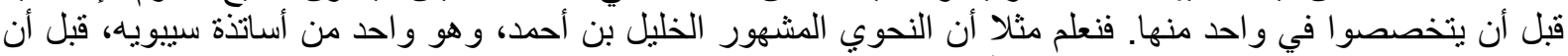
ينصرف إلى النحو ، تعلم الحديث و الفقه عن أيوب السخنياني، الذي كان فقيها من فقهاء البصرة ومحدثا من محدثيها."

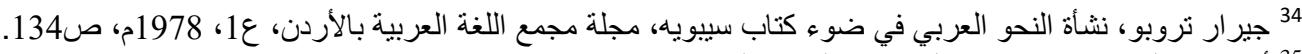

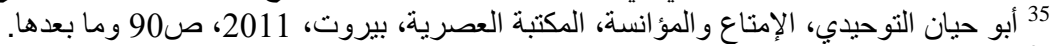

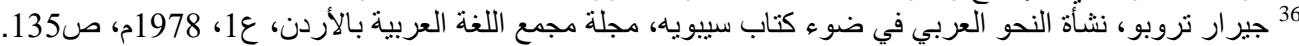

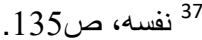
(38) تفسه، ص136.

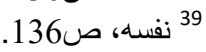

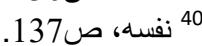

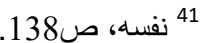




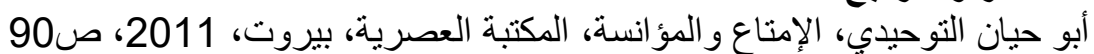

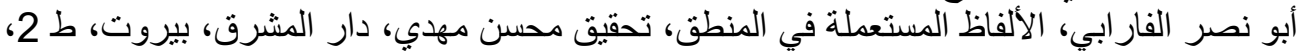

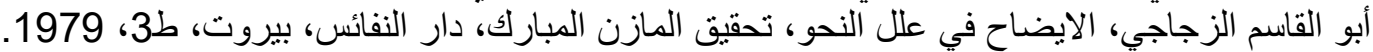

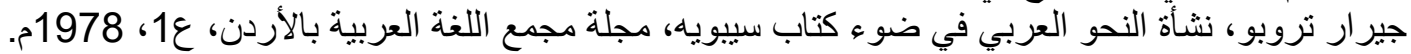

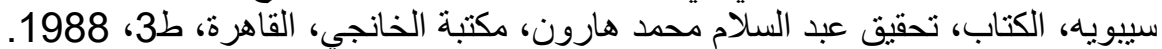

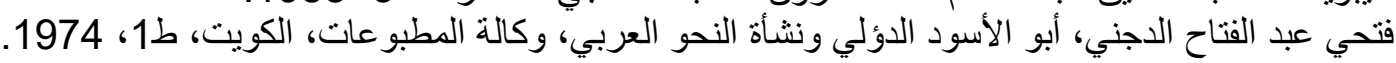

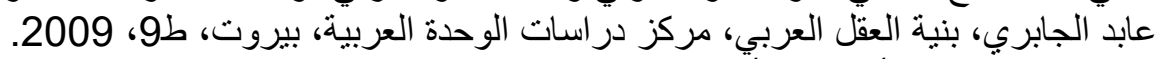

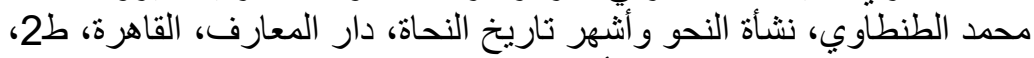
محمد خير الحلو اني، بين منطق أرسطو والنحو العربي، مجلة المورد، العراف، العار، المجلدو، العدد1، 1980. 